\title{
Latarjet procedure enables $73 \%$ to return to play within 8 months depending on preoperative SIRSI and Rowe scores
}

\author{
Yoann Bohu ${ }^{1} \cdot$ Pierre Abadie $^{2}$ - Floris van Rooij ${ }^{3}$ - Luca Nover $^{3}$. Société Française de Traumatologie du Sport . \\ Julien Berhouet ${ }^{4}$. Alexandre Hardy ${ }^{1,5}$
}

Received: 24 November 2020 / Accepted: 25 January 2021 / Published online: 20 March 2021

(c) The Author(s) 2021

\begin{abstract}
Purpose Systematic reviews report return to play (RTP) within 5.8 months (range, 3-8) following the Latarjet procedure, but the factors that influence RTP remain unknown. The present study aimed to report the rate and time of return to play (RTP) during the first 8 months following the Latarjet procedure, and to determine the influence of sport type or patient characteristics.

Methods The authors retrospectively collected the records of patients that underwent Latarjet procedures for anterior shoulder instability between 2015 and 2017. Patients were excluded if they had any concomitant rotator cuff tendon lesions, or previous ipsilateral shoulder surgery. The authors retrieved patient demographics, time from injury to surgery, type of sport practiced (overhead/non-overhead, contact/non-contact), as well as pre- and postoperative Western Ontario Shoulder Instability index (WOSI), Shoulder Instability-Return to Sport After Injury index (SIRSI), and Rowe score.

Results A total of 217 patients (217 shoulders) were eligible for inclusion, comprising 184 males and 33 females, aged $26.8 \pm 7.3$ years at index surgery. The main sport practiced prior to surgery involved overhead $(n=173,80 \%)$ and/or contact $(n=152,70 \%)$ activities. By 8 month follow-up, 158 patients $(73 \%)$ resumed their main sport, at a mean of $5.1 \pm 1.5$ months. Multivariable analysis revealed that RTP was more likely in patients with higher preoperative Rowe score (OR, 1.02; $p=0.024)$ and SIRSI score (OR, 1.02; $p=0.008)$.

Conclusions By 8 months following the Latarjet procedure, $73 \%$ of patients had resumed their main sport. The likelihood of RTP was significantly associated with preoperative Rowe and SIRSI scores, but not with sport type.
\end{abstract}

Level of evidence IV.

Keywords Latarjet $\cdot$ Anterior shoulder instability $\cdot$ Return to play

The members of the Société Française de Traumatologie du Sport is mentioned in "Acknowledgments" section.

Yoann Bohu

ybohu@ chirurgiedusport.com

Floris van Rooij

journals@ resurg.eu

Clinique du Sport Paris V, Ramsay Santé, Paris, France

2 Clinique du Sport de Bordeaux-Merignac, Mérignac, France

3 ReSurg SA, 22 Rue Saint Jean, 1260 Nyon, Switzerland

4 Service d'Orthopédie Hôpital Trousseau CHRU, Tours, France

5 Ambroise Paré Hospital, Boulogne-Billancourt, France

\section{Introduction}

Anterior shoulder instability often requires surgical treatment, particularly in young athletes that wish to resume sports [5, 29, 31]. The most common surgical procedures involve arthroscopic labral or capsular repair [27, 32], and open or arthroscopic bone-block procedures [9, 21], which transfer the coracoid process through a subscapularis split to the anteroinferior margin of the glenoid $[12,40]$.

The Latarjet technique is a bone-block procedure that gained considerable popularity in recent years, as it proved effective at preventing recurrent dislocations [2, 8, 19], while allowing rapid recovery and return to play (RTP) [3, $8,19,23]$. The Latarjet procedure has also demonstrated satisfactory long-term outcomes in young recreational and competitive athletes $[5,13,20,41]$, despite comparatively 
high complication rates, including pain due to soft-tissue impingements [17], neurologic impairments, and bone-block nonunion or malposition $[11,13,15,18,25,39]$.

One of the main concerns for a young athlete undergoing surgery is if and when they will be able to RTP, notably resuming their main sport at preinjury or preoperative level. Recent studies revealed that up to $50 \%$ of athletes are able to RTP within 6 months following the Latarjet procedure $[10,14,30]$, though it remains unclear whether RTP depends on the type of sport or on other demographic and surgical factors. The purpose of this study was to: (i) report the rate and time of RTP during the first 8 months following primary Latarjet procedures performed to treat anterior shoulder instability; and (ii) determine whether the rate and time of RTP are associated with type of sport or patient characteristics. The hypothesis was that the rate and time of RTP are associated with neither type of sport nor patient characteristics.

\section{Materials and methods}

The authors retrospectively collected the records of patients that underwent Latarjet procedures over a 2-year period (July 2015-June 2017) at 9 centers. All patients provided informed consent for their participation in this study, which had been approved by the institutional review board in advance (IRB\# COS-RGDS-2020-05-022-BOHU-Y, Ramsay Santé Comité d'Ethique; +33 (0)1 878622 97; Dr Sylviane Olschwang). The indication for a Latarjet procedure was anterior shoulder instability with a history of at least 1 dislocation, regardless of sports type, activity level, or bone loss. Patients were excluded if they had any concomitant rotator cuff tendon lesions, or previous ipsilateral shoulder surgery. A total of 217 patients ( 217 shoulders) met the criteria for inclusion.

\section{Preoperative assessment}

The authors retrieved patient demographics, work activity level, and time from injury to surgery, if the accident occurred during sport, type of sport practiced (overhead/ non-overhead, contact/non-contact), preoperative dislocation and subluxation episodes, as well as preoperative clinical scores including Western Ontario Shoulder Instability index (WOSI) [24], Shoulder Instability-Return to Sport After Injury index (SIRSI) [16], and Rowe score [36]. Sports such as handball, rugby, basketball, and judo were considered as overhead contact; tennis, ski, badminton, volley as overhead non-contact; football as non-overhead contact; jogging, cycling as non-overhead non-contact.

\section{Surgical techniques}

Depending on surgeon experience, the two techniques were used to perform the Latarjet procedure: a mini-open technique with a commercially available drill guide (Arthrex $\mathrm{GmbH}$, Munich, Germany) and two $4 \mathrm{~mm}$ cannulated cancellous screws as based on the modified Latarjet procedure described by Walch and Boileau [38], or an arthroscopic technique with a specific guide (DePuy, Indiana, United States) and two $3.5-\mathrm{mm}$ cannulated cancellous screws as described by Lafosse et al. [26]

\section{Postoperative rehabilitation}

Shoulders were immobilized with a sling for a minimum of 2 weeks to prevent pain, and all patients started self-rehabilitation exercises 1 day after surgery following a standard protocol [34], followed by a rehabilitation program supervised by a physiotherapist. Patients were allowed to return to daily activities after 1 month, but allowed to resume sports after 3 months only if they had recovered mobility. Patients were allowed to RTP if they were pain-free, with full ROM, regardless of time since index surgery.

\section{Postoperative evaluation}

Patients underwent clinical examination at 8 months, during which the authors recorded immobilization time, whether and when a patient returned to their main preoperative sport, as well as postoperative clinical scores including WOSI, SIRSI, and Rowe. The timeframe of 8 months was based on the findings of a systematic review by Hurley et al. [22] who reported that the mean time for RTP following the Latarjet procedure was 5.8 months, ranging from 3.2 to 8 months.

\section{Statistical analysis}

A priori sample size calculation was performed to determine whether the rate of the RTP would be significantly different among overhead athletes vs. non-overhead athletes. From experience with the Latarjet procedure, the proportion of overhead athletes is typically double that of non-overhead athletes. Based on the findings of Baverel et al. [5] and Beranger et al. [6], the expected rates of RTP between two groups of athletes with different characteristics would be $50 \%$ in overhead athletes vs. $75 \%$ in non-overhead athletes. To determine whether such a difference is statistically significant, with alpha of 0.05 and a power of 0.80 , a minimum of 70 overhead athletes and 35 non-overhead athletes is required. The normality of distributions was assessed using Shapiro-Wilk tests. For normally distributed continuous data, differences between groups were evaluated using 
ANOVA, while for not-normally distributed data, differences were evaluated using Kruskal-Wallis tests. Pre- and postoperative scores were evaluated using paired $t$ tests or Wilcoxon signed-rank tests. For categorical data, differences between groups were evaluated using Fisher's exact tests. Uni- and multivariable regression analyses were performed to determine the influence on rate and time to RTP of 10 independent preoperative variables (age at surgery, BMI, sex, type of sport, dislocation episodes, time from 1st dislocation to surgery, completed rehabilitation program, type of surgery, preoperative scores including WOSI, SIRSI, and Rowe). Statistical analysis was performed using R version 3.4.3 (R Foundation for Statistical Computing, Vienna, Austria). $p$ values $<0.05$ were considered statistically significant.

Table 1 Patient demographics

\begin{tabular}{|c|c|c|}
\hline & \multicolumn{2}{|c|}{ Cohort $n=217$ shoulders } \\
\hline & $n(\%)$ Mean \pm SD & Range \\
\hline Age at operation (years) & $26.8 \pm 7.3$ & $(15-62)$ \\
\hline BMI $\left(\mathrm{kg} / \mathrm{m}^{2}\right)$ & $23.8 \pm 3.0$ & $(18-39)$ \\
\hline Years from first dislocation to surgery & $4.4 \pm 4.9$ & $(0-26)$ \\
\hline Male sex & $184(85 \%)$ & \\
\hline Operation on dominant arm & $109(50 \%)$ & \\
\hline \multicolumn{3}{|l|}{ Work activity level } \\
\hline Active & $97(45 \%)$ & \\
\hline Semi-sedentary & $45(21 \%)$ & \\
\hline Sedentary & $75(35 \%)$ & \\
\hline \multicolumn{3}{|l|}{ Type of sport } \\
\hline Overhead-contact & $136(63 \%)$ & \\
\hline Overhead-non-contact & $37(17 \%)$ & \\
\hline Non overhead—contact & $16(7 \%)$ & \\
\hline Non overhead—non-contact & $28(13 \%)$ & \\
\hline Accident during sport & $182(84 \%)$ & \\
\hline \multicolumn{3}{|l|}{ Accident due to } \\
\hline Fall on shoulder & $78(36 \%)$ & \\
\hline Fall on elbow & $20(9 \%)$ & \\
\hline Movement without fall & $77(35 \%)$ & \\
\hline Contact without fall & $39(18 \%)$ & \\
\hline Unknown & $3(1 \%)$ & \\
\hline \multicolumn{3}{|l|}{ Preoperative dislocation episodes } \\
\hline 1 & $74(34 \%)$ & \\
\hline $2-6$ & $132(61 \%)$ & \\
\hline 7 or more & $11(5 \%)$ & \\
\hline \multicolumn{3}{|l|}{ Preoperative subluxation episodes } \\
\hline 1 & $53(24 \%)$ & \\
\hline $2-6$ & $73(34 \%)$ & \\
\hline 7 or more & $91(42 \%)$ & \\
\hline Hill-Sachs lesion & $99(46 \%)$ & \\
\hline Glenoid anterior defect & $103(47 \%)$ & \\
\hline
\end{tabular}

\section{Results}

The 217 patients assessed comprised 184 males (85\%) and 33 females (15\%) aged $26.8 \pm 7.3$ years (range, $15-62)$ at index surgery (Table 1). For the majority of patients, the main sport practiced prior to surgery involved overhead $(n=173,80 \%)$ and/or contact $(n=152,70 \%)$ activities (Table 2). Among 173 overhead athletes, 109 (63\%) underwent surgery on their dominant arm. Twenty-seven complications were observed including hematoma $(n=23,11 \%)$, graft displacement $(n=3,1.4 \%)$, and paresthesia $(n=1$, $0.5 \%)$. Only 140 patients (65\%) completed the full rehabilitation program under the supervision of a physiotherapist, while the remaining 77 patients (35\%) did not complete the full rehabilitation program.

By 8 months' follow-up, 158 patients (73\%) had resumed their main sport, at a mean of $5.1 \pm 1.5$ months (Fig. 1). Of the 158 patients that returned to sport, $106(67 \%)$ returned to their preoperative level, while $14(9 \%)$ returned to a higher level, and 38 (24\%) returned to a lower level. Patients performing overhead contact had resumed their main sport at a mean of $5.0 \pm 1.5$ months, overhead non-contact at $5.3 \pm 1.5$ months, non-overhead contact at $5.2 \pm 1.7$ months, and non-overhead non-contact at $5.2 \pm 1.5$ months (n.s.). Comparing pre- and postoperative scores, WOSI improved from $55 \pm 21$ to $86 \pm 13(p<0.001)$, SIRSI improved from $51 \pm 26$ to $70 \pm 23(p<0.001)$, and Rowe improved from $52 \pm 25$ to $87 \pm 16(p<0.001)$. Of the 173 patients that practiced overhead sports, $122(70 \%)$ had resumed their main sport, while of the 44 patients that practiced non-overhead sports, $36(82 \%)$ had resumed their main sport (n.s.). Of the 152 patients that practiced contact sports, $113(74 \%)$ had resumed their main sport, while of the 65 patients that practiced non-contact sports, 45 (69\%) had resumed their main sport (n.s.). The type of main sport was not significantly associated with either time for RTP (n.s.), WOSI score (n.s.), SIRSI (n.s.), or Rowe score (n.s.) (Fig. 2).

Univariable analysis revealed that RTP was more likely for patients with higher preoperative Rowe score (OR 1.02, $p=0.014)$, and tended to be more likely for patients with higher preoperative SIRSI score (OR 1.01, n.s.) (Table 3; 4). Multivariable analysis confirmed that RTP was more likely for patients with higher preoperative Rowe score (OR 1.02, $p=0.024)$ and SIRSI score (OR 1.02, $p=0.008)$.

\section{Discussion}

The most important findings of this study were that, by 8 months following the Latarjet procedure, $73 \%$ of patients resumed their main sport, and that the mean time for RTP was $5.1 \pm 1.5$ months. The likelihood of RTP was 


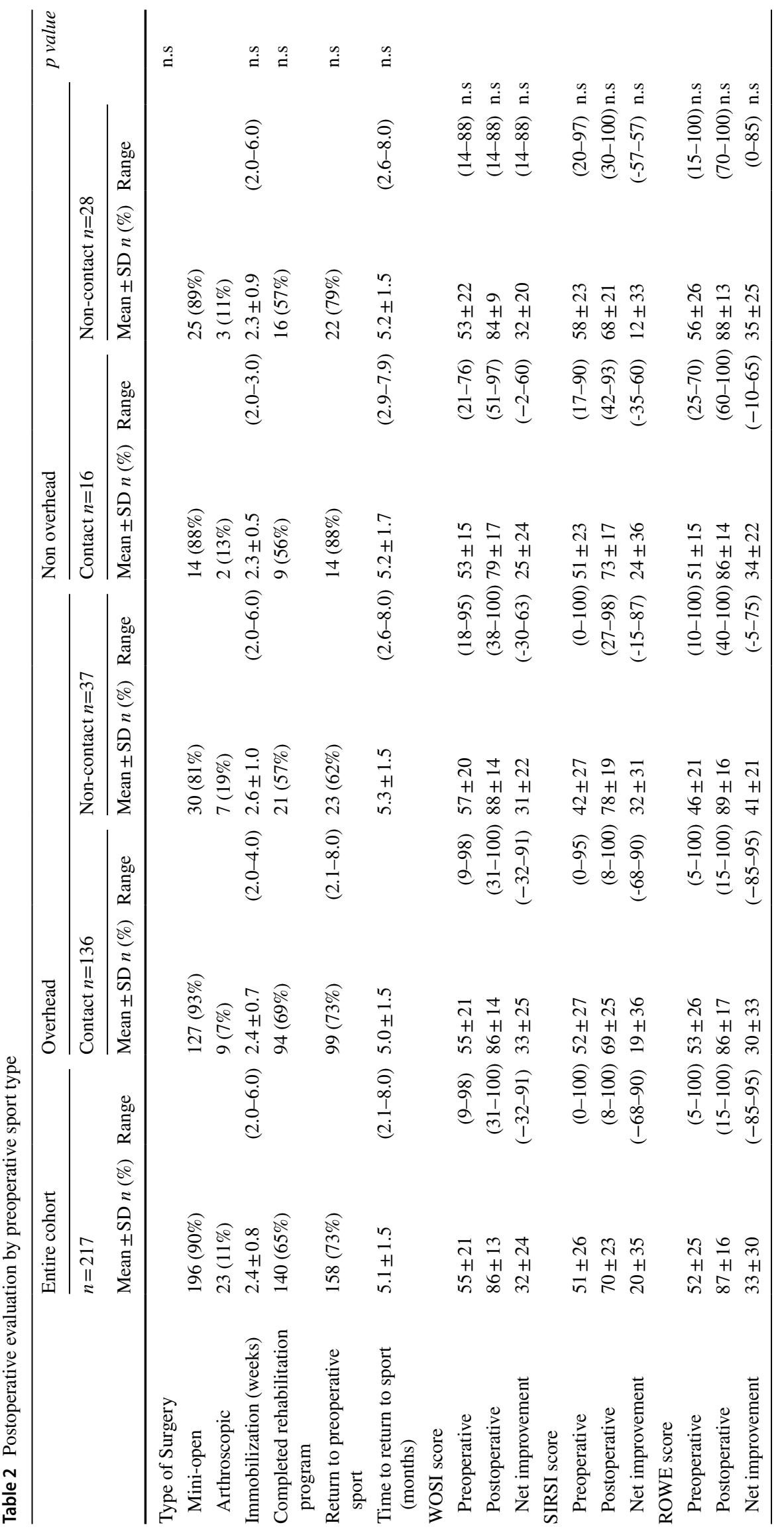




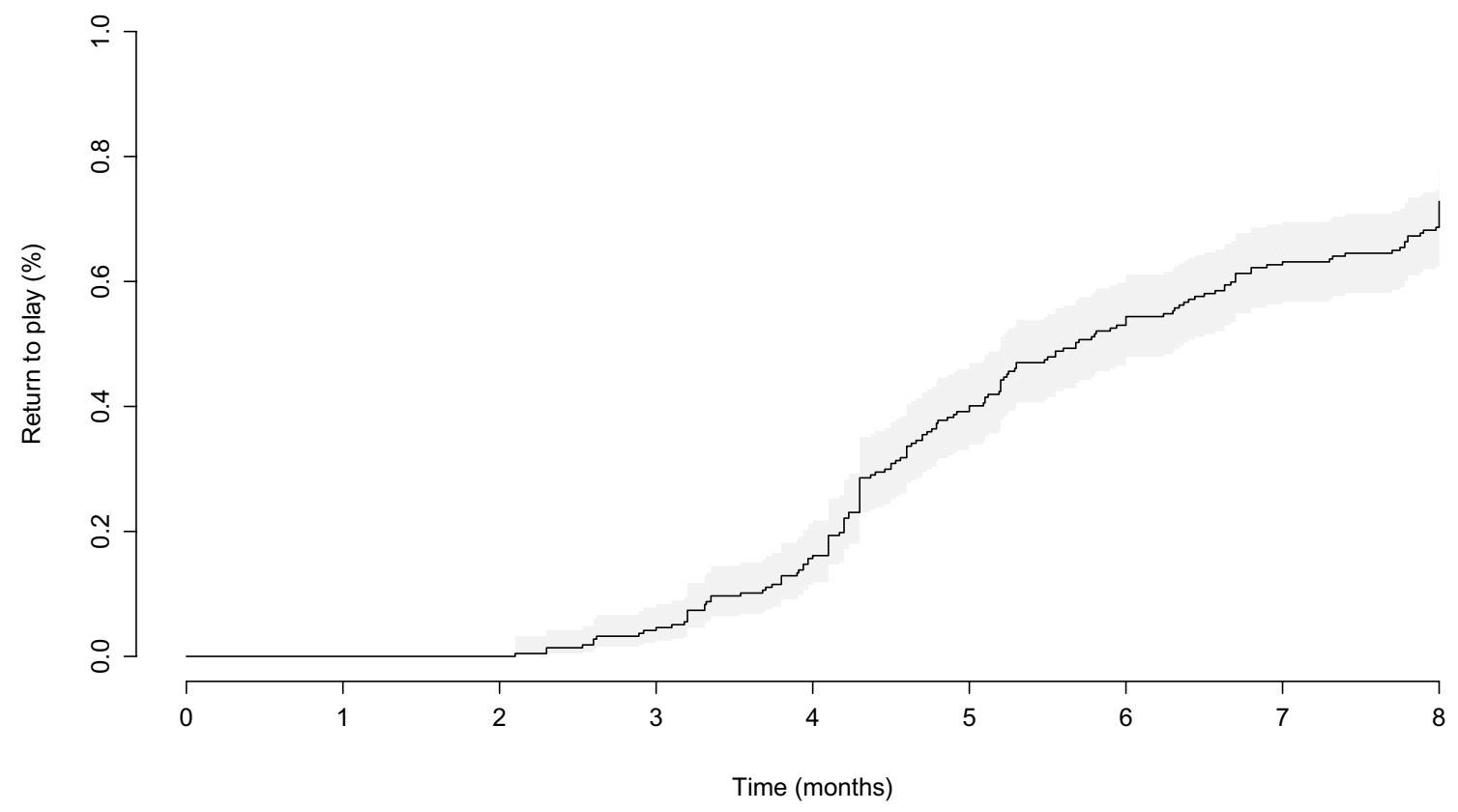

Fig. 1 Following the Latarjet procedure, patients started resuming their main sport during the third postoperative month, and by the eight postoperative month, $73 \%$ of patients had resumed their main sport

Fig. 2 Pre- and postoperative WOSI score by type of sport

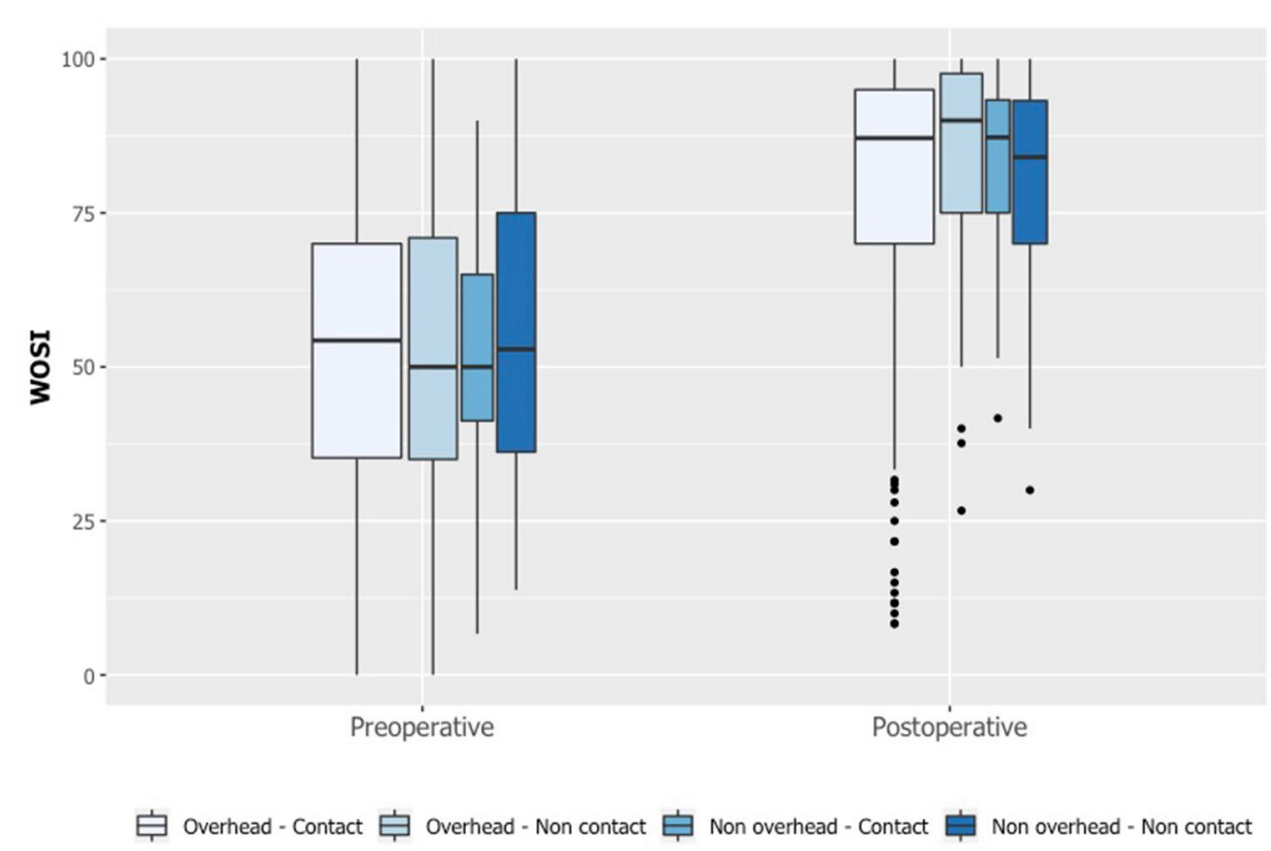

significantly associated with preoperative Rowe and SIRSI scores, but not with the type of sport. The same proportion of patients resumed contact and non-contact sports, while a greater proportion of patients resumed non-overhead sports than overhead sports, although there was no statistically significant difference. Therefore, the present findings do not entirely support the hypothesis that the rate and time of RTP are associated with neither type of sport nor patient characteristics (Fig. 3, 4).

In a systematic review of 31 articles on surgical procedures to treat anterior shoulder instability, Hurley et al. [22] reported that at a mean follow-up of 83.5 months (range, 21-240), $73 \%$ of patients resumed their sports at the same or higher level. In another systematic review, Abdul-Rassoul et al. [1] reported that at a mean follow-up of 61 months 
Table 3 Uni- and multivariable regression analysis for likelihood of return to sport
Table 4 Uni- and multivariable regression analysis for time (months) to return to sport

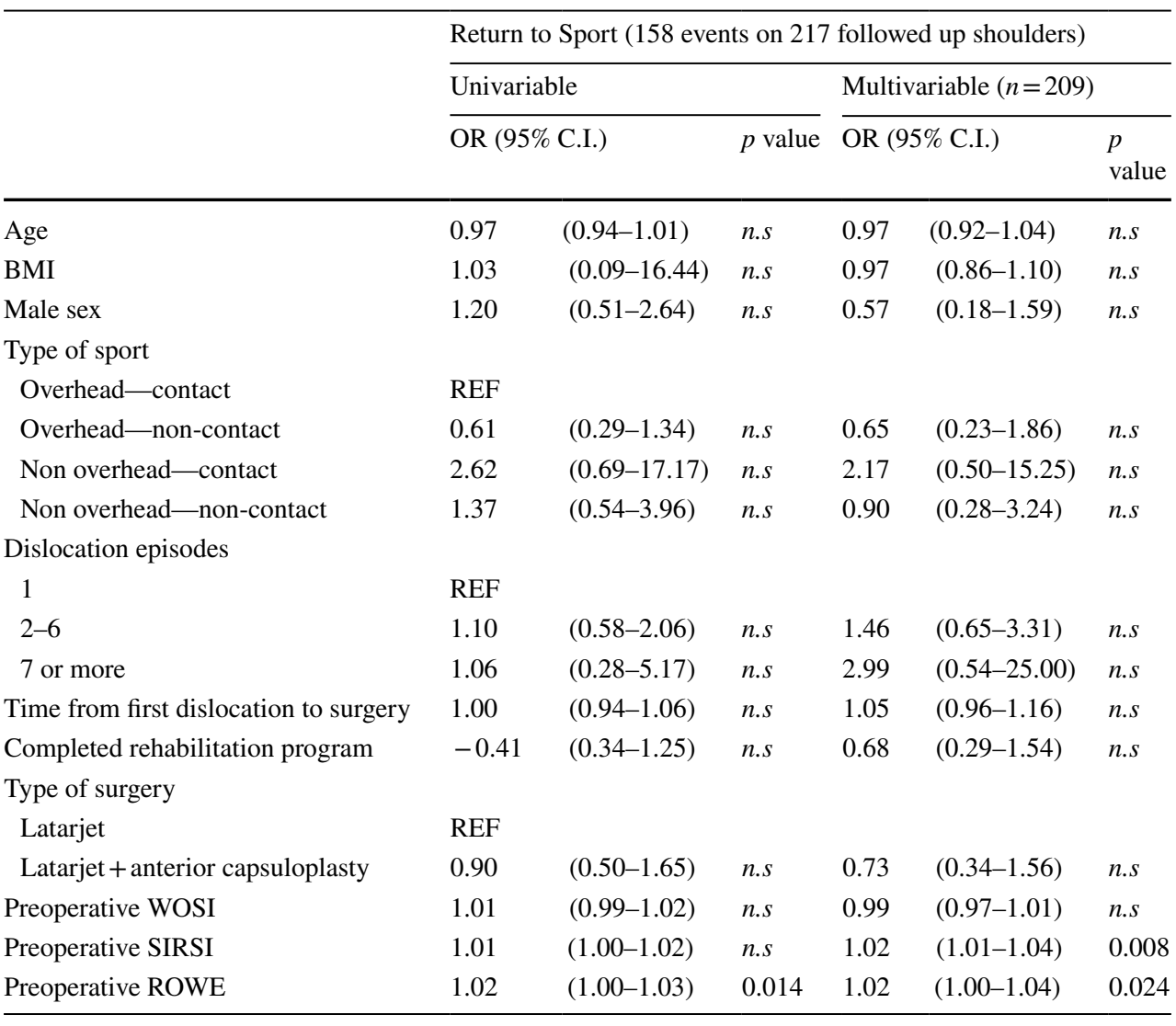

C.I. Confidence interval

\begin{tabular}{|c|c|c|c|c|}
\hline \multirow[t]{3}{*}{ Variables } & \multicolumn{4}{|c|}{ Return to Sport (158 patients of 217 followed up shoulders) } \\
\hline & \multicolumn{2}{|l|}{ Univariable } & \multicolumn{2}{|c|}{ Multivariable $(n=143)$} \\
\hline & $\beta(95 \%$ C.I. $)$ & $p$ value & $\beta(95 \%$ C.I. $)$ & $p$ value \\
\hline Age & $0.0(0.7-0.3)$ & n.s & $0.0(0.0-0.1)$ & $n . s$ \\
\hline BMI & $0.0(0.0-0.0)$ & n.s & $0.1(0.0-0.2)$ & n.s \\
\hline Male sex & $-0.2(-0.9-0.5)$ & n.s & $-0.5(-1.3-0.4)$ & n.s \\
\hline \multicolumn{5}{|l|}{ Type of sport } \\
\hline Overhead-contact & REF & & & \\
\hline Overhead-non-contact & $0.2(-0.5-0.9)$ & n.s & $0.4(-0.4-1.3)$ & n.s \\
\hline Non overhead-contact & $0.2(-0.7-1.0)$ & n.s & $0.3(-0.7-1.3)$ & n.s \\
\hline Non overhead-non-contact & $0.1(-0.6-0.8)$ & n.s & $0.3(-0.6-1.1)$ & n.s \\
\hline \multicolumn{5}{|l|}{ Dislocation episodes } \\
\hline 1 & REF & & & \\
\hline $2-6$ & $0.2(-0.3-0.7)$ & n.s & $0.2(-0.5-0.8)$ & n.s \\
\hline 7 or more & $0.7(-0.4-1.8)$ & n.s & $0.9(-0.3-2.1)$ & n.s \\
\hline Time from first dislocation to surgery & $0.0(-0.1-0.0)$ & n.s & $0.0(-0.1-0.0)$ & n.s \\
\hline Completed rehabilitation program & $0.1(-0.4-0.6)$ & n.s & $0.0(-0.1-0.0)$ & n.s \\
\hline \multicolumn{5}{|l|}{ Type of surgery } \\
\hline Latarjet & REF & & & \\
\hline Latarjet + anterior capsuloplasty & $-0.2(0.7-0.3)$ & n.s & $-0.1(-0.7-0.5)$ & n.s \\
\hline Preoperative WOSI & $0.0(0.0-0.0)$ & n.s & $0.0(0.0-0.0)$ & n.s \\
\hline Preoperative SIRSI & $0.0(0.0-0.0)$ & n.s & $0.0(0.0-0.0)$ & n.s \\
\hline Preoperative ROWE & $0.0(0.0-0.0)$ & n.s & $0.0(0.0-0.0)$ & n.s \\
\hline
\end{tabular}

$\beta$, expected difference; C.I. confidence interval 
Fig. 3 Pre- and postoperative SIRSI score by type of sport

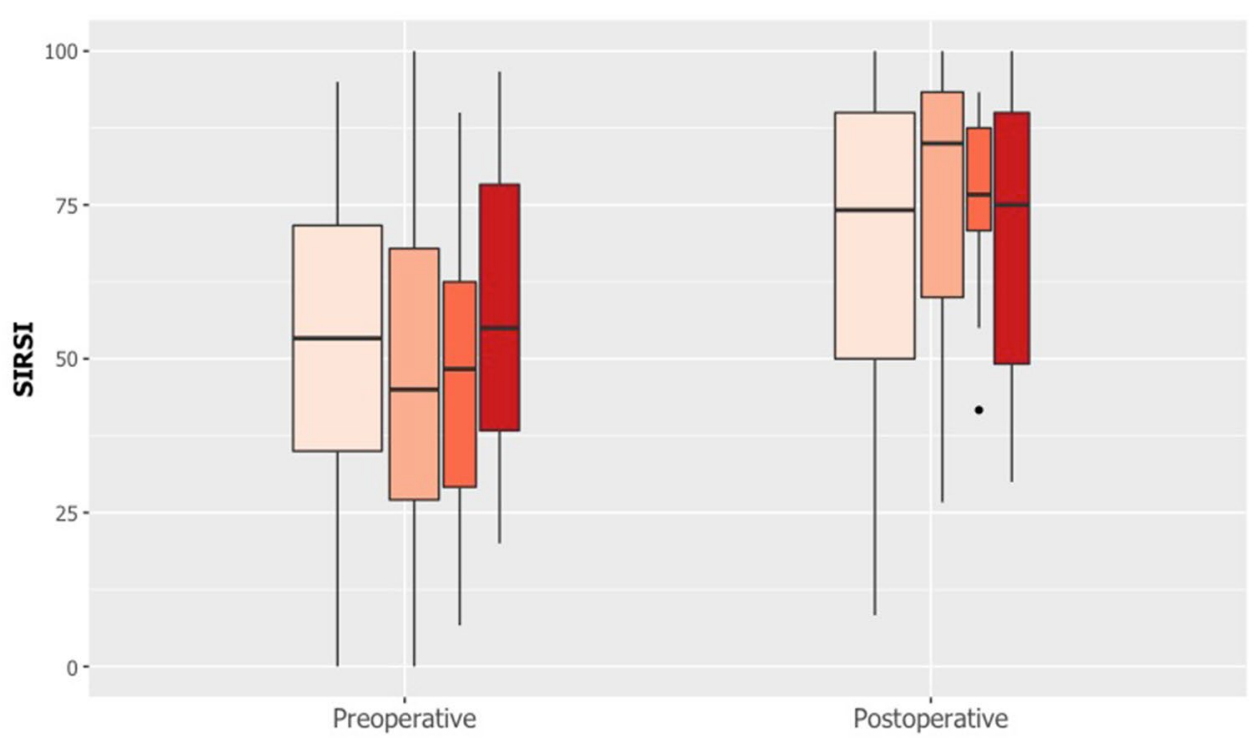

Overhead - Contact 官 Overhead - Non contact 官 Non overhead - Contact
Fig. 4 Pre- and postoperative Rowe score by type of sport

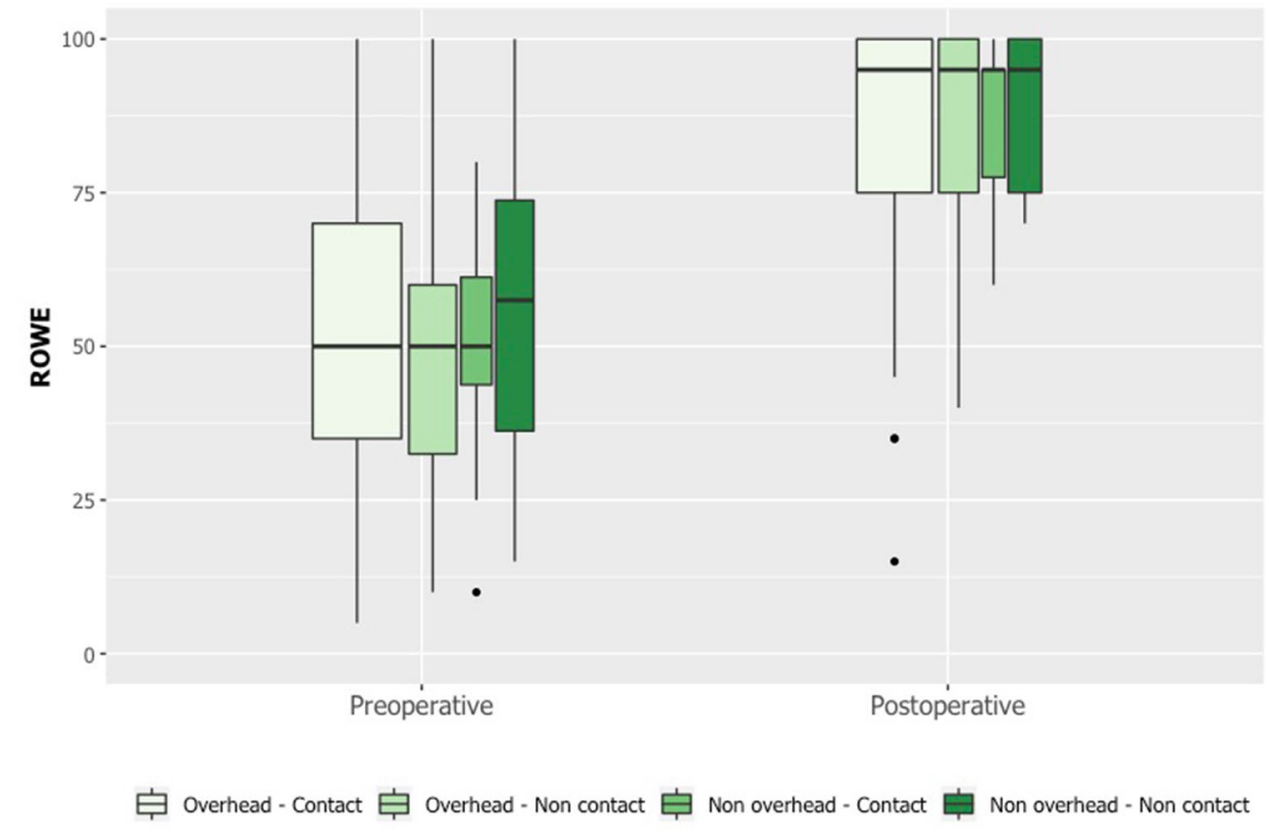

(range, 12-144), 84\% of patients resumed their sports after the Latarjet procedure, the majority of which returned to their preinjury level. Privitera et al. [30] reported that at a follow-up of 52 months (range, 24-120), 49\% of patients returned to their competitive sport at their preinjury level, and $14 \%$ of patients returned to their competitive sport at a decreased level. Rossi et al. [33] revealed that at a followup of 58 months (range, 24-108 months), 96\% of patients were able to return to sports, of which $91 \%$ returned to their preinjury level. Baverel et al. [5] found that at a mean follow-up of 46 months, almost twice as many competitive athletes $(79 \%)$ returned to their preinjury level or higher, compared to recreational athletes (43\%). Even though the Latarjet procedure does decrease shoulder mobility, it has minimal impact on RTP [35], and may decrease progression of osteoarthritis [37].

In the present series, the mean time for RTP was $5.1 \pm 1.5$ months, with no significant differences among the 4 types of sports. Rossi et al. [33] reported that time for RTP after the Latarjet procedure was 3.7 months for patients who performed non-contact/non-overhead sports, compared to 5.1 months for those that performed high-impact/contact 
sports, 5.4 months for overhead sports, and 5.8 months for martial arts. Frantz et al. [14] found that at 6 months followup, $55 \%$ of patients failed to meet criteria for RTP, defined as $<20^{\circ}$ loss of ROM as compared with baseline values in any plane, and/or lower strength grade than the baseline value. Several systematic reviews report return to play (RTP) within 5.8 months following the Latarjet procedure [21, 28], but the type of sport and preoperative patient characteristics that influence RTP remain unknown.

In the present study, uni- and multivariable analyses revealed that patients with better preoperative Rowe and SIRSI scores were more likely to resume their main sport. Gerometta et al. [16] reported that the patient's psychological readiness should be taken into account when deciding on RTP [2]. The SIRSI score, like the Anterior Cruciate Ligament-Return to Sport after Injury (ACL-RSI) score [7], enables identification of patients who might have psychological difficulties returning to play. A recent systematic review by Ardern et al. [4] identified studies evaluating the psychological factors associated with RTP, which include motivation, self-confidence, and fear. Fear is the main negative emotion influencing RTP, and a common reason for patients not to resume sports. Self-determination theory ensures that the patients perceive that they are in control of resuming sports, by reducing external pressure and overcoming fear by involving the patients in setting rehabilitation as well as RTP goals, and therefore promoting their sense of confidence and autonomy.

The results of the present study must be interpreted with the following limitations in mind. This was a retrospective multicentric study that included 9 centers, which may have introduced multiple confounding factors, such as different surgical techniques, including a majority of mini-open procedures $(n=196)$, and a minority of arthroscopic procedures $(n=21)$. Furthermore, the numbers of patients excluded because of concomitant rotator cuff tears or surgical antecedents on the ipsilateral shoulder was not documented. This study, with its short follow-up, was not designed to determine the recurrence of dislocations after the Latarjet procedure or to report radiological outcomes, but rather to quantify the rate and time for RTP within 8 months regarding different types of sport. It is worth noting that the rate and mean time for RTP could both be greater if the study was performed at longer follow-up. Nevertheless, the present series is one of the largest cohorts on outcomes following the Latarjet procedure, which enabled detailed analysis of independent variables that could improve or compromise rate of RTP. The present findings could help surgeons provide objective advice to patients regarding resuming sports after the Latarjet procedure, depending on sport type and preoperative scores.

\section{Conclusion}

The most important findings of this study were that, by 8 months following the Latarjet procedure, $73 \%$ of patients resumed their main sport, and that the mean time for RTP was $5.1 \pm 1.5$ months. The likelihood of RTP was significantly associated with preoperative Rowe and SIRSI scores, but not with the type of sport. The same proportion of patients resumed contact and non-contact sports, while a greater proportion of patients resumed non-overhead sports than overhead sports, although there was no statistically significant difference.

Acknowledgements Collaborators of the Société Française de Traumatologie du Sport: Jean Kany, Philippe Colotte, François Kelberine, Didier Fontes, Charles Edouard Thelu, and Matthieu Sanchez.

\section{Compliance with ethical standards}

Conflict of interest All authors declare that they have no competing interests in relation to this study.

Funding The authors are grateful to Ramsay Sante for funding the statistical analysis and manuscript preparation for this study.

Ethical approval The ethics committee of Ramsay Santé approved the study in advance (IRB\# COS-RGDS-2020-05-022-BOHU-Y).

Informed consent All patients provided informed consent for their participation in this study.

Open Access This article is licensed under a Creative Commons Attribution 4.0 International License, which permits use, sharing, adaptation, distribution and reproduction in any medium or format, as long as you give appropriate credit to the original author(s) and the source, provide a link to the Creative Commons licence, and indicate if changes were made. The images or other third party material in this article are included in the article's Creative Commons licence, unless indicated otherwise in a credit line to the material. If material is not included in the article's Creative Commons licence and your intended use is not permitted by statutory regulation or exceeds the permitted use, you will need to obtain permission directly from the copyright holder. To view a copy of this licence, visit http://creativecommons.org/licenses/by/4.0/.

\section{References}

1. Abdul-Rassoul H, Galvin JW, Curry EJ, Simon J, Li X (2019) Return to sport after surgical treatment for anterior shoulder instability: a systematic review: response. Am J Sports Med 47(3):NP24-NP27. https://doi.org/10.1177/0363546519825642

2. Ali ZS, Hurley ET, Jamal MS, Horan MP, Montgomery C, Pauzenberger L, Millett PJ, Mullett H (2020) Low rate of recurrent instability following the open Latarjet procedure as a revision procedure for failed prior stabilization surgery. Knee Surg Sports Traumatol Arthrosc. https://doi.org/10.1007/s00167-020-06155-6

3. An VV, Sivakumar BS, Phan K, Trantalis J (2016) A systematic review and meta-analysis of clinical and patient-reported outcomes following two procedures for recurrent traumatic anterior instability of the shoulder: Latarjet procedure vs. Bankart repair. 
J Shoulder Elbow Surg 25(5):853-863. https://doi.org/10.1016/j. jse.2015.11.001

4. Ardern CL, Taylor NF, Feller JA, Webster KE (2013) A systematic review of the psychological factors associated with returning to sport following injury. Br J Sports Med 47(17):1120-1126. https://doi.org/10.1136/bjsports-2012-091203

5. Baverel L, Colle PE, Saffarini M, Anthony Odri G, Barth J (2018) Open latarjet procedures produce better outcomes in competitive athletes compared with recreational athletes: a clinical comparative study of 106 athletes aged under 30 years. Am J Sports Med 46(6):1408-1415. https://doi.org/10.1177/0363546518759730

6. Beranger JS, Klouche S, Bauer T, Demoures T, Hardy P (2016) Anterior shoulder stabilization by Bristow-Latarjet procedure in athletes: return-to-sport and functional outcomes at minimum 2-year follow-up. Eur J Orthop Surg Traumatol 26(3):277-282. https://doi.org/10.1007/s00590-016-1751-5

7. Bohu Y, Klouche S, Lefevre N, Webster K, Herman S (2015) Translation, cross-cultural adaptation and validation of the French version of the anterior cruciate ligament-return to sport after injury (ACL-RSI) scale. Knee Surg Sports Traumatol Arthrosc 23(4):1192-1196. https://doi.org/10.1007/s00167-014-2942-4

8. Cerciello S, Corona K, Morris BJ, Santagada DA, Maccauro G (2019) Early outcomes and perioperative complications of the arthroscopic latarjet procedure: systematic review and meta-analysis. Am J Sports Med 47(9):2232-2241. https://doi.org/10.1177/ 0363546518783743

9. Chillemi C, Guerrisi M, Paglialunga C, Salate Santone F, Osimani M (2020) Latarjet procedure for anterior shoulder instability: a 24-year follow-up study. Arch Orthop Trauma Surg. https://doi. org/10.1007/s00402-020-03426-2

10. Ciccotti MC, Syed U, Hoffman R, Abboud JA, Ciccotti MG, Freedman KB (2018) Return to play criteria following surgical stabilization for traumatic anterior shoulder instability: a systematic review. Arthroscopy 34(3):903-913. https://doi.org/10.1016/j. arthro.2017.08.293

11. Delaney RA, Freehill MT, Janfaza DR, Vlassakov KV, Higgins LD, Warner JJ (2014) 2014 neer award paper: neuromonitoring the Latarjet procedure. J Shoulder Elbow Surg 23(10):1473-1480. https://doi.org/10.1016/j.jse.2014.04.003

12. Ersen A, Birisik F, Ozben H, Atalar AC, Sahinkaya T, Seyahi A, Demirhan M (2018) Latarjet procedure using subscapularis split approach offers better rotational endurance than partial tenotomy for anterior shoulder instability. Knee Surg Sports Traumatol Arthrosc 26(1):88-93. https://doi.org/10.1007/s00167-017-4480-3

13. Frank RM, Gregory B, O'Brien M, Bernardoni E, Verma NN, Cole BJ, Nicholson GP, Romeo AA (2019) Ninety-day complications following the Latarjet procedure. J Shoulder Elbow Surg 28(1):88-94. https://doi.org/10.1016/j.jse.2018.06.022

14. Frantz TL, Everhart JS, Cvetanovich GL, Neviaser A, Jones GL, Hettrich CM, Wolf BR, Baumgarten KM, Bollier MJ, Bravman JT, Kuhn JE, Ma CB, Marx RG, McCarty EC, Ortiz SF, Zhang AL, Bishop JY (2020) Are Patients who undergo the Latarjet procedure ready to return to play at 6 months? A multicenter orthopaedic outcomes network (moon) shoulder group cohort study. Am J Sports Med 48(4):923-930. https://doi.org/10.1177/03635 46520901538

15. Gartsman GM, Waggenspack WN, O'Connor DP, Elkousy HA, Edwards TB (2017) Immediate and early complications of the open Latarjet procedure: a retrospective review of a large consecutive case series. J Shoulder Elbow Surg 26(1):68-72. https://doi. org/10.1016/j.jse.2016.05.029

16. Gerometta A, Klouche S, Herman S, Lefevre N, Bohu Y (2018) The shoulder instability-return to sport after injury (SIRSI): a valid and reproducible scale to quantify psychological readiness to return to sport after traumatic shoulder instability. Knee Surg
Sports Traumatol Arthrosc 26(1):203-211. https://doi.org/10. 1007/s00167-017-4645-0

17. Godenèche A, Merlini L, Roulet S, Le Chatelier M, Delgrande D, Saffarini M, Métais P (2020) Screw removal can resolve unexplained anterior pain without recurrence of shoulder instability after open Latarjet procedures. Am J Sports Med 48(6):1450 1455. https://doi.org/10.1177/0363546520916171

18. Griesser MJ, Harris JD, McCoy BW, Hussain WM, Jones MH, Bishop JY, Miniaci A (2013) Complications and re-operations after Bristow-Latarjet shoulder stabilization: a systematic review. J Shoulder Elbow Surg 22(2):286-292. https://doi.org/10.1016/j. jse.2012.09.009

19. Horner NS, Moroz PA, Bhullar R, Habib A, Simunovic N, Wong I, Bedi A, Ayeni OR (2018) Open versus arthroscopic Latarjet procedures for the treatment of shoulder instability: a systematic review of comparative studies. BMC Musculoskelet Disord 19(1):255. https://doi.org/10.1186/s12891-018-2188-2

20. Hurley ET, Jamal MS, Ali ZS, Montgomery C, Pauzenberger L, Mullett H (2019) Long-term outcomes of the Latarjet procedure for anterior shoulder instability: a systematic review of studies at 10-year follow-up. J Shoulder Elbow Surg 28(2):e33-e39. https:// doi.org/10.1016/j.jse.2018.08.028

21. Hurley ET, Manjunath AK, Matache BA, Jia NW, Virk M, Jazrawi LM, Meislin RJ (2020) No difference in 90-day complication rate following open versus arthroscopic Latarjet procedure. Knee Surg Sports Traumatol Arthrosc. https://doi.org/10.1007/ s00167-020-06301-0

22. Hurley ET, Montgomery C, Jamal MS, Shimozono Y, Ali Z, Pauzenberger L, Mullett H (2019) Return to play after the Latarjet procedure for anterior shoulder instability: a systematic review. Am J Sports Med 47(12):3002-3008. https://doi.org/10.1177/ 0363546519831005

23. Kee YM, Kim JY, Kim HJ, Lim CT, Rhee YG (2018) Return to sports after the latarjet procedure: high return level of non-collision athletes. Knee Surg Sports Traumatol Arthrosc 26(3):919 925. https://doi.org/10.1007/s00167-017-4775-4

24. Kirkley A, Griffin S, Mclintock H, Ng L (1998) The development and evaluation of a disease-specific quality of life measurement tool for shoulder instability. The Western Ontario Shoulder Instability Index (WOSI). Am J Sports Med 26(6):764-772. https://doi. org/10.1177/03635465980260060501

25. Kordasiewicz B, Małachowski K, Kiciński M, Chaberek S, Boszczyk A, Marczak D, Pomianowski S (2019) Intraoperative graft-related complications are a risk factor for recurrence in arthroscopic Latarjet stabilisation. Knee Surg Sports Traumatol Arthrosc 27(10):3230-3239. https://doi.org/10.1007/ s00167-019-05400-x

26. Lafosse L, Lejeune E, Bouchard A, Kakuda C, Gobezie R, Kochhar T (2007) The arthroscopic Latarjet procedure for the treatment of anterior shoulder instability. Arthroscopy 23(11):1242.e12411245. https://doi.org/10.1016/j.arthro.2007.06.008

27. Levy DM, Cole BJ, Bach BR Jr (2016) History of surgical intervention of anterior shoulder instability. J Shoulder Elbow Surg 25(6):e139-150. https://doi.org/10.1016/j.jse.2016.01.019

28. Nadeem IM, Vancolen S, Horner NS, Bedi A, Alolabi B, Khan M (2020) Return to sport after coracoid bone block transfer for shoulder instability: a systematic review. Hss J 16(3):296-306. https://doi.org/10.1007/s11420-019-09720-Z

29. Neyton L, Young A, Dawidziak B, Visona E, Hager JP, Fournier Y, Walch G (2012) Surgical treatment of anterior instability in rugby union players: clinical and radiographic results of the Latarjet-Patte procedure with minimum 5-year follow-up. J Shoulder Elbow Surg 21(12):1721-1727. https://doi.org/10.1016/j.jse.2012. 01.023

30. Privitera DM, Sinz NJ, Miller LR, Siegel EJ, Solberg MJ, Daniels SD, Higgins LD (2018) Clinical outcomes following the Latarjet 
procedure in contact and collision athletes. J Bone Joint Surg Am 100(6):459-465. https://doi.org/10.2106/jbjs.17.00566

31. Ranalletta M, Rossi LA, Bertona A, Tanoira I, Hidalgo IA, Maignon GD, Bongiovanni SL (2018) Modified Latarjet without capsulolabral repair in rugby players with recurrent anterior glenohumeral instability and significant glenoid bone loss. Am J Sports Med 46(4):795-800. https://doi.org/10.1177/0363546517 749586

32. Rao AJ, Verma NN, Trenhaile SW (2017) The "Floating Labrum": bankart lesion repair with anterior capsular extension using 2 anterior working portals. Arthrosc Tech 6(5):e1607-e1611. https://doi.org/10.1016/j.eats.2017.06.017

33. Rossi LA, Bertona A, Tanoira I, Maignon GD, Bongiovanni SL, Ranalletta M (2018) Comparison between modified latarjet performed as a primary or revision procedure in competitive athletes: a comparative study of 100 patients with a minimum 2-year follow-up. Orthop J Sports Med 6(12):2325967118817233. https:// doi.org/10.1177/2325967118817233

34. Roulet S, Borel F, Franger G, Liotard JP, Michelet A, Godenèche A (2019) Immediate self-rehabilitation after open Latarjet procedures enables recovery of preoperative shoulder mobility at 3 months. Knee Surg Sports Traumatol Arthrosc 27(12):3979-3988. https://doi.org/10.1007/s00167-019-05635-8

35. Sinha S, Kar S, Naik AK, Kumar J, Goyal R, Jain VK, Arya RK (2021) Decreased motion with normal strength after Latarjet procedure has minimal impact on return to activity. Knee Surg Sports Traumatol Arthrosc. https://doi.org/10.1007/s00167-020-06414-6

36. Skare Ø, Schrøder CP, Mowinckel P, Reikerås O, Brox JI (2011) Reliability, agreement and validity of the 1988 version of the
Rowe score. J Shoulder Elbow Surg 20(7):1041-1049. https:// doi.org/10.1016/j.jse.2011.04.024

37. Verweij LPE, Pruijssen EC, Kerkhoffs G, Blankevoort L, Sierevelt IN, van Deurzen DFP, van den Bekerom MPJ (2020) Treatment type may influence degree of post-dislocation shoulder osteoarthritis: a systematic review and meta-analysis. Knee Surg Sports Traumatol Arthrosc. https://doi.org/10.1007/s00167-020-06263-3

38. Walch G, Boileau P (2000) Latarjet-Bristow procedure for recurrent anterior instability. Tech Shoulder Elbow Surg 1(4):256-261

39. Woodmass JM, Welp KM, Chang MJ, Borque KA, Wagner ER, Warner JJP (2018) A reduction in the rate of nerve injury after Latarjet: a before-after study after neuromonitoring. J Shoulder Elbow Surg 27(12):2153-2158. https://doi.org/10.1016/j.jse.2018. 05.028

40. Young AA, Baba M, Neyton L, Godeneche A, Walch G (2013) Coracoid graft dimensions after harvesting for the open Latarjet procedure. J Shoulder Elbow Surg 22(4):485-488. https://doi.org/ 10.1016/j.jse.2012.05.036

41. Zhang AL, Montgomery SR, Ngo SS, Hame SL, Wang JC, Gamradt SC (2014) Arthroscopic versus open shoulder stabilization: current practice patterns in the United States. Arthroscopy 30(4):436-443. https://doi.org/10.1016/j.arthro.2013.12.013

Publisher's Note Springer Nature remains neutral with regard to jurisdictional claims in published maps and institutional affiliations. 